\author{
Mohan Raj Sharma \\ Founder Editor-in-Chief \\ Nepal Journalof Neuroscience
}

Date received: $20 / 4 / 18$

Date accepted: 25/4/18

\section{Fourteen years of Nepal \\ Journal of Neuroscience: Brief History}

F ounded in 2004, Nepal Journal of Neuroscience has become the national voice of Nepalese neuroscience community. During last 14 years, it has come a long way and now is established as one of the leading journals published from Nepal. This narrative will briefly describe how it came into existence and how it was in the firstfew of years of its life.

After getting training from the University of Washington and working closely with the Journal of Neurosurgery publishing group I developed a strong desire to start a journal in Neurosurgery in Nepal. I knew very well then that the path would not be easy.There were two major obstacles. Firstly, back then, neurosurgeons were so few in number that sustainability would have become a huge issue. Secondly we did not have any neurosurgical or neurological organization. Hence, we did not have a legal parent for this still unborn child. To resolve the first obstacle, some of us involved in the field of Neuroscience (neurologists, neurosurgeons, radiologists, emergency physicians, etc.) gathered in one of the restaurants in Kathmandu and thought about the need of a neuroscience journal in Nepal.

To mitigate the second issue, a small committee of people working at theInstitute of Medicine, Tribhuvan University was made. The name of the committee as Neurosurgical Forum. Dr. Ram Ghimire, Dr. Jagdish Prasad Agrawal, Dr. PVS Rana, Dr. Suman Amatya were the committee members who were very instrumental in giving me a 'push' to start and run the journal.

We kn0w that "every big journey starts with the first step." Weeks of anxious planning and many sleepless nights resulted in the publication of the first issue (print as well as free online version).

The first issue was published in July 2004 with thirteen articles (Figure 1). The first issue was published as, 'Journal of Neuroscience' but from subsequent issues, the name was changed to 'Nepal Journal of Neuroscience' to reflect the country of origin. The journal was launched by the Vice Chancellor of then Royal Nepal Academy of
Science and Technology (RONAST) Professor Dayananda Bajracharya in Tribhuvan University Teaching Hospital.
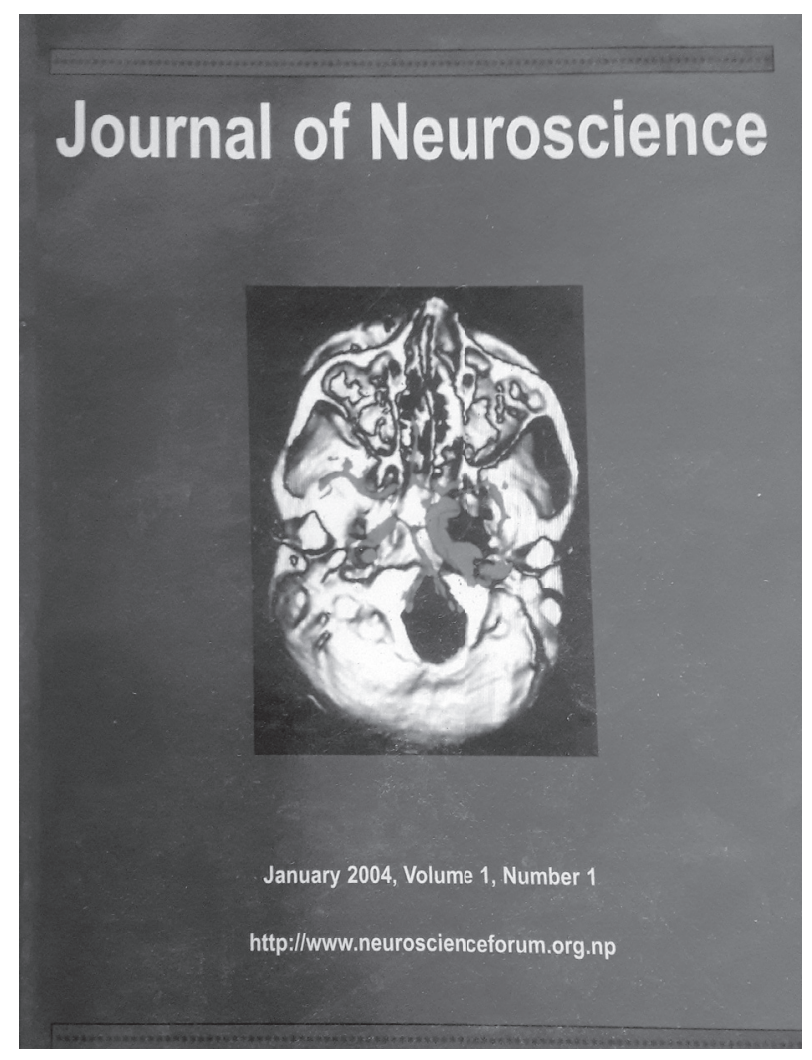

Figure1. the cover of the first issue of the journal.

Budget to run the journal was arranged from the donation from the individuals involved in the Neurosurgical Forum. In the later years, we started to get advertisement from the pharmaceuticals company.

Subsequently, getting good quality articles became the most burning problem in the sustainability of the journal. Initial few issues were published primarily based on solicited articles from the doctors and scientists I personally knew. Some noted personalities were directly contacted via email for the first time. We were very lucky 
to get the positive response from many. For the third issue, we contactedProfessor Bryan Jennet from Glasgow to contribute an article. He was very generous in submitting an article on Glasgow Coma Scale (GCS) along with an original photograph of GCS recording while they were conducting the feasibility of using GCS back in 70's (Figure 2). We proudly put that photograph in our cover page. That was the most gratifying moment for me as the Editor-in-Chief for 11 years.

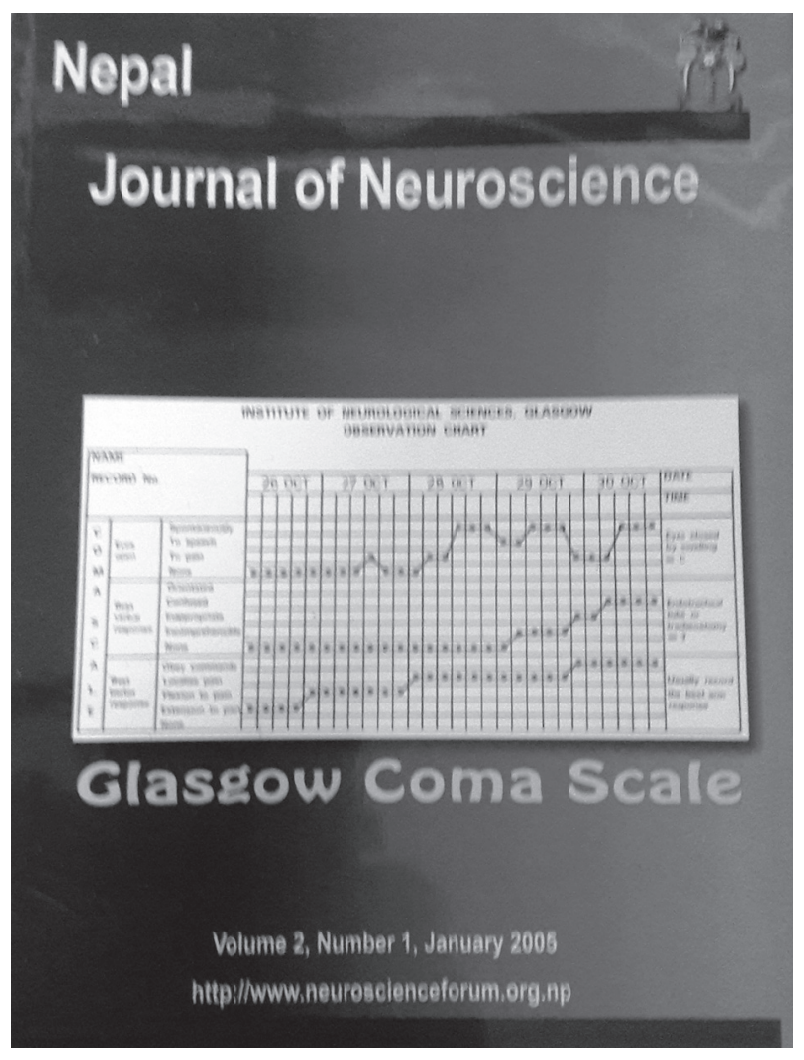

Figure 2. cover of the journal with the GCS

In 2007, Nepalese Society of Neurosurgeons (NESON) came into existence. Right from the outset this society expressed its desire to be involved/ and be the official society publishing

the journal. On the other side, for any journal, being an official publication of national society always carries more weight in terms of contribution of articles and ownership. So in 2008, the Neurosurgical Forum officially handed the journal over to NESON. So, since 2008, it has become the official journal of NESON.

In the initial years, though there were many people who gave a lot of moral support, there were very few who actually had time to work day and night to 'assemble' and 'deliver." Right from getting the articles to distributing journals to various places. At one point I had thought of no longer running it. But 'killing' your own child is a serious offence. One positive happenstance changed this. Dr. Prabin Shrestha had just come from Japan after completing his education and training from Japan and he showed a strong desire to be involved in the journal. So he joined us as executive editor in 2008 .

In 2015, I resigned as editor-in-chief after running it for 12 years as people more capable than me were already there. Dr. Shrestha took over in 2016 and ran the journal for 2 years. In September 2017, Dr. Yam Bahadur Roka, another very capable and academic person was appointed as the Editor-in-Chief. I am very proud to state that he has been handling the journal very efficiently and professionally.

Challenges to get support will always be there but this journal has had the unique ability to thrive despite many setbacks. Now with the third editor-in chief running the journal, I think we have conquered the majority of odds. Being the official journal of NESON, our path is welllighted and our journey well-provisioned.

In the history of publishing journal. 14 years may not be a long time. But our journal has already made a small history. I wish every success for the current Editor-inChief in raising the standard of this journal in the coming years further.

(Part of this writing is based on the earlier publication on similar theme). ${ }^{1}$

\section{References}

1. Sharma MR. Change that we believe in. Nepal Journal of Neuroscience : 8 73, 2011 